\title{
Physiological Actions of Potent Drugs
}

\section{López-Muñoz $\mathbf{F}^{*}$}

Faculty of Health Sciences, Camilo José Cela University, Madrid, Spain

*Corresponding author: Faculty of Health Sciences, Camilo José Cela University, C/ Castillo de Alarcón, 49, Urb. Villafranca del Castillo, 28692 Villanueva de la Cañada, Madrid, Spain, Tel: 34-91-815-3131; Fax: 34-91-860-9343; E-mail: francisco.lopez.munoz@gmail.com

Received date: July 23, 2016; Accepted date: July 25, 2016; Published date: July 29, 2016

Copyright: (c) 2016 López-Muñoz F, et al. This is an open-access article distributed under the terms of the Creative Commons Attribution License, which permits unrestricted use, distribution, and reproduction in any medium, provided the original author and source are credited.

\section{Editor Note}

Journal of Clinical \& Experimental Pharmacology eases the gap between the medical practice and laboratory science. It explains the way physiological actions of chemical agents or drugs on the living organisms. It emphasizes the significance of the registered medical practitioners in order to create awareness and to maximize the drug effects while minimizing the side effects.

Nagata et al., in their study, demonstrated that an essential oil preparation from hiba (Thujopsis dolabrata) exerts antitumor effects against gastric cancer cells. The experiment used nude mice model to establish gastric cancer and apoptotic change of these cancer cells and analyzed the TUNEL reaction. This investigation could find the volatile components of HEO, with its anti-tumor effects on gastric cancer. The study has also revealed that hinokitiol is not the only bioactive molecule, but there are other components which may equally serve as antitumor factor [1].

Saghiv et al., evaluated the systolic and diastolic blood pressures measured by both direct and indirect methods, which provide readings for symptom-limited exercise on treadmill and bicycle. The study results suggest that the indirect method tends to bias low compared with direct method at peak treadmill and bicycle exercises; hence it is not valid for the assessment of diastolic pressure in hypertensive patients [2].

Islam et al., designed a study to investigate the antihyperglycemic and antidyslipidemic effects and hepatoprotectivity of the fixed dose combination of metformin and pitavastatin on alloxan induced diabetic rats. The results of the present study suggest that efficacy of combination of metformin and pitavastatin in patients with diabetic dyslipidemia is positive and also exhibits increased hepatoprotectivity [3].

Alebachew et al., in his short communication, discussed the position of clinical pharmacists in delivering advanced pharmacy practice education and services [4]. Finally, Emamuzo et al., investigated the effects of a single adult human intramuscular bolus of chloroquine on the blood glucose level in fasting normoglycemic Wistar rats [5].

\section{References}

1. Nagata T, Fujino Y, Toume K, Xiao Long L, Yamaguchi T, et al. (2016) Anticancer Effect in Volatile Components of Hiba Essential Oil (Thujopsis dolabrata). Clin Exp Pharmacol 6: 214.

2. Saghiv M, Goldhammer E, Michael S, Ben-Sira D, Hanson P (2016) Comparison of Direct vs. Indirect Blood Pressure Measurements on Treadmill and Bicycle in Hypertensive Responders. Clin Exp Pharmacol 6: 215.

3. Islam T, Nasrin S, Rashid M, Sultana T, Kawsar H, et al. (2016) Beneficiary Effect of Combination Therapy of Metformin and Pitavastatin Drug on Alloxan Induced Diabetic Rats Comparing to Single Drug Therapy. Clin Exp Pharmacol 6: 217.

4. Alebachew M, Tileku M, Beyene A, Berihun D, Asefa T, et al. (2016) The Position of Clinical Pharmacists in Delivering Advanced Pharmacy Practice Education and Services: Short Communication. Clin Exp Pharmacol 6: 216.

5. Emamuzo ED, Onyemulu EC, Raphael NC, Delesi KH, Chukwumweike OA, et al. (2016) Single Adult-human Equivalent Dose of Intramuscular Chloroquine did not Lower Blood Glucose Level in Fasted Wistar Rats. Clin Exp Pharmacol 6: 213. 